\title{
Hydrogen Leakage Sensing and Control: (Review)
}

\author{
Yousef SH Najjar* and Mashareh S \\ Founding Chairman of Mechanical Engineering Department, Founding Director of The Energy Center, Jordan University of Science and \\ Technology, Jordan \\ *Corresponding author: Professor Yousef SH Najjar, Founding Chairman of Mechanical Engineering Department, Founding \\ Director of The Energy Center, Jordan University of Science and Technology, Jordan
}

\begin{tabular}{l}
\hline ARTICLE INFO \\
\hline Received: 幽 September 25, 2019 \\
Published: 幽 October 11, 2019 \\
\hline Citation: Yousef SH Najjar, Mashareh S \\
Hydrogen Leakage Sensing and Control: \\
(Review). Biomed J Sci \& Tech Res 21(5) \\
2019. BJSTR. MS.ID.003670.
\end{tabular}

Keywords: Hydrogen Leakage Sensing and Control: (Review)

\begin{abstract}
Hydrogen fuel, as a clean source of energy, and the best alternative source for fossil fuels is not more dangerous than other common fuels, including gasoline and natural gas. Hydrogen is the smallest molecule and the lightest element, and it has the greatest probability to leak as well. Thus, detection becomes more challenging than other gases for safety considerations. Like any flammable fuel, hydrogen can be very dangerous under certain conditions. However, it can be handled safely by understanding its behavior, observing simple guidelines and monitoring its concentration by suitable safety sensors used for leak detection purposes. The purpose of this article is to provide an overview of different hydrogen sensing principles, its operation mechanisms, applications, and limitations. Also, the recent improvements of low- cost solid-state hydrogen detection sensors were highlighted. Then the suitable actions and actuators used to control the leakage and keep the hydrogen concentration in the safe limits were discussed. Moreover, observing the most recently researched gas sensing technologies such as integrating palladium into commonly used sensing technologies was investigated. Palladium is a very sensitive material for hydrogen and improves sensor's performance and sensitivity.

Abbreviations: CB: Catalytic Bead; NFPA: National Fire Protection Association; CGS: Combustible Gas Sensor; NG: Natural gas; COMB: Combined Sensors; Pd: Palladium; DOE: Department of Energy; PEM: Proton Exchange Membrane; EC: Electrochemical Sensors: PS: Porous Silicon; FV: Forced Ventilation; PPM: Part Per Million; GC: Gas chromatography; QCM: Quartz Crystal Microbalance Sensor; HE: Helium; RH: Relative Humidity; $\mathrm{H}_{2}$ : Hydrogen Molecular Form; SAW: Surface Acoustic Wave; LEL: Lower Explosive Limit; TC: Thermal Conductivity; LFL: Lower Flammability Limit; t10: The time it takes the sensor to read $10 \%$ of the test gas concentration; MEMS: Micro-ElectroMechanical Systems; t90: The time it takes the sensor to read $90 \%$ of the test Gas Concentration; MOS: Metal Oxide Semiconductor Sensor; MS: Mass Spectrometry; UEL: Upper Explosive Limit by vol.\%; MOX: Metal Oxide Sensor; NF: Non-flammable; UFL: Upper Flammability Limit by vol.\%; NV: Natural Ventilation
\end{abstract}

\section{Introduction}

Hydrogen is the smallest chemical element found in all organic materials and fossil fuels; however, it's not available in nature in its pure molecular form. $\mathrm{H}_{2}$, in pure molecular form is the lightest gas, colorless, odorless, and nontoxic. It is also considered as a clean fuel because when it is burned there are no emissions besides water vapor [1]. Pure hydrogen is widely used as a clean source of energy in many applications, such as space exploration, chemical industries, and in transportation using fuel cells to provide the vehicles with electrical energy and reduces the huge dependence on traditional fossil fuels [2]. By Comparison with traditional fuels, hydrogen has three times the energy exists in one gasoline mass unit, also very wide flammable range (4-75 vol. \%), seven times wider than methane, with very low ignition energy $(0.02 \mathrm{~mJ})$. Therefore, it is a very important issue to ensure the safety in utilization of $\mathrm{H}_{2}$ sensing and detection of $\mathrm{H}_{2}$ leakage, and infrastructure should be designed and prepared carefully [3], storage and transportation of $\mathrm{H}_{2}$ should be considered as well. Consequently, accurate, sensitive, rapid response, wide measuring range and other parameters of the 
$\mathrm{H}_{2}$ sensor have great importance in recent studies and attractive for researchers [4].

Hydrogen energy is expected to be the best alternative for fossil fuels taking into consideration leakage of hydrogen. Nowadays, some hydrogen vehicles have already been produced but unfortunately, because of risks of $\mathrm{H} 2$ leakage, it is still not ready to be used widely as a conventional fuel. Leakage of $\mathrm{H}_{2}$ is serious problem because, the resulted gas mixture of $\mathrm{H}_{2}$ with air is flammable in wide range comparing to gasoline mixture and may cause fire or explosion as the upper and lower flammability limits of hydrogen with other common fuels shown in Table 1 . The leakage of $\mathrm{H}_{2}$ can be caused by several factors [5] such as, $\mathrm{H}_{2}$ embrittlement, that caused by long term contact between the container materials and $\mathrm{H}_{2}$, which later can cause cracking and leakage [6]. Moreover, the broad usage of $\mathrm{H}_{2}$ in industrial applications increases the possibilities of accidental leakage such as in storage, production, and transportation fields. The source shape of leakage is the key factor which affects the leakage characterization and has been studied by many researchers. There are two classes of $\mathrm{H}_{2}$ leakage; a rapid leakage causing combustion which can modeled by Classic turbulent jet flame, and slow unignited leakage that is very attractive for researchers [4,7-9].

Table 1: Upper and lower flammability limits for hydrogen comparing with common fuels.

\begin{tabular}{|c|c|c|}
\hline Fuel & LFL (\%) & UFL (\%) \\
\hline Gasoline & 1.4 & 7.6 \\
\hline Propane & 2.1 & 10.1 \\
\hline Ethane & 3 & 12.4 \\
\hline Hydrogen & 4 & 75 \\
\hline Methane & 5 & 15 \\
\hline
\end{tabular}

K Ramamurthi et al. [7] studied the cloud mixture formation from $\mathrm{H}_{2}$ and air resulted in an open area from leakage at different temperature and the effects of atmospheric conditions on the dispersion of $\mathrm{H}_{2}$ using Gaussian model. K. Ramamurthi et al. [7] found that a flammable mixture cloud can be created in stable atmospheric conditions, such as low wind speeds and temperature, in winter clear sky. While S Vudumu et al. [8] studied the flammability limits and transient behavior of the mixture of $\mathrm{H}_{2}$ with air. They studied two conditions, sudden release at the bottom of cylinder, and the jet release using software simulation.

\section{Main Properties of Hydrogen}

In the nature, Hydrogen is the most abundant chemical element, and can be produced from many resources such as water, biomass, coal, and a natural gas as a feed stock, using different sources of energy, including renewable energy, such as solar, wind, and nuclear energy. Thus, a lot of countries in the world will have the opportunity to produce this fuel locally. Otherwise, hydrogen is environmentally friendly source of energy, because the only byproducts of using this fuel are water, heat, and electricity, also as it is replaces the fossil fuels, greenhouse emissions will be decreased and the quality of the air will be improved.

\section{Comparing of Safety Properties of Hydrogen with other Fuels}

For more than 40 years, $\mathrm{H}_{2}$ has widely been used in industry, and as fuel for space exploration. During that, infrastructure has been developed to produce, store, and transport $\mathrm{H}_{2}$ safely. Hydrogen like other flammable gases should be handled carefully for safety requirements [10]. The main advantages and disadvantages of hydrogen with respect to other most commonly used fuels are listed in Table 2. Hydrogen is the lightest gas (14 times lighter than air) and the smallest molecule; therefore, it has the greatest tendency to release [11]. A hydrogen leakage can be more dangerous than other gases and its detection becomes more challenging [3]. $\mathrm{H}_{2}$ diffusivity is rapid as 3.8 times faster than $\mathrm{NG}$ (natural gas); when $\mathrm{H}_{2}$ released, it is quickly dilute and at rise speed two times faster than $\mathrm{He}$ (helium), six times faster than NG which is $20 \mathrm{~m} / \mathrm{s}$ as mentioned in Table 2. So, if there is no structure to contain the rising gas, such as roof, or ventilation opening, $\mathrm{H}_{2}$ will not cumulating around a source of leakage. Also, $\mathrm{H}_{2}$ to become at dangerous concentration it should be confined. That's why Industry considered these properties in designing a hydrogen-based structures, by allowing $\mathrm{H}_{2}$ to escape away from the source in case of any unexpected leak. M Royle and D Willoughby [9] quantify the hazards and risks of H2 leak experimentally and specify details on jet releases to decrease safety distance in this area.

Table 2: Main advantages and disadvantages of hydrogen with respect to other gases.

\begin{tabular}{|c|c|}
\hline Advantages & Disadvantages \\
\hline Diffusivity: 3.8 times faster than NG & $\begin{array}{l}\text { Odorless, colorless, } \\
\text { tasteless }\end{array}$ \\
\hline $\begin{array}{l}\text { Rises speed (of hydrogen gas in air): } 20 \\
\text { m/s ( } 6 \text { times faster than NG and } 2 \text { times } \\
\text { faster than } \mathrm{He} \text { ) }\end{array}$ & Explosive range: $18.3-59 \%$ \\
\hline $\begin{array}{l}\text { Stoichiometric (most easily ignited): } 29 \% \\
\text { of H2 in air }\end{array}$ & Ignition energy: $0.02 \mathrm{~mJ}$ \\
\hline Radiant heat: Less radiant heat & Flammability range: $4-75 \%$ \\
\hline Nontoxic & $\begin{array}{l}\text { Blue flame (invisible in day } \\
\text { light). }\end{array}$ \\
\hline Non-poisonous & \\
\hline
\end{tabular}

Hydrogen also is odorless, colorless and tasteless; hydrogen leakage can't be detected by smelling because it is odorless gas and moves away from where any nose might detect it. Hydrogen has tendency to rise quickly. Thus, an indoors leak would briefly accumulate near the ceiling then moves towards the corners. For that and other reasons, industry often uses $\mathrm{H}_{2}$ sensors to help detect hydrogen leaks. These sensors revealed a high safety record by using them for decades. By comparison, NG is also odorless, colorless and tasteless, but to make it detectable by human, industry adds a sulfurcontaining odorant. Unfortunately, all known odorants contaminate the fuel cells. Accordingly, Researchers are investigating other methods that might be used for hydrogen detection, such tracers, new odorant technology, advanced sensors and others. On the other hand, hydrogen combustion basically produces heat and water. 
Because of the absence of carbon and the existence of water vapor which is absorbing heat when hydrogen burns, hydrogen burns have considerably less radiant heat in respect to a hydrocarbon fire. As the flame emits low levels of heat, the risk of secondary fires is lower. This fact has a great impact to rescue workers and the public. And like any other flammable fuel, hydrogen may combust. But its buoyancy, diffusivity and small molecular size make it hard to enclose and form a combustible mixture. Hydrogen fire to start; needs an adequate concentration of hydrogen, the presence of an ignition source, and the right amount of oxidizer (such as oxygen) all at the same time. Hydrogen has a wide flammability range (4-74\% in air) and very low energy required to ignite hydrogen $(0.02 \mathrm{~mJ})$. However, at concentrations below $10 \%$ the ignition energy required is high, similar to the energy required to ignite NG (natural gas) and gasoline in their respective flammability ranges, making hydrogen realistically more difficult to ignite near the lower flammability limit. On the other hand, if the hydrogen concentration increased toward the stoichiometric mixture (most easily ignited mixture) of $29 \%$ hydrogen (in air), the ignition energy drops to about one fifteenth of that required to ignite NG (or one tenth for gasoline).

An explosion cannot occur in any tank or container that contains only $\mathrm{H}_{2}$ [12]. Hydrogen can be explosive at 18.3- 59\% concentrations. Although the range is wide, it is important to realize that gasoline can be more dangerous than hydrogen since the possibility of gasoline explosion is at much lower concentrations, $1.1-3.3 \%$. In addition, there is a very little chance for hydrogen to explode in an open air, because of its affinity to rise quickly.

\section{An Overview: Hydrogen Measuring Technologies}

Several $\mathrm{H}_{2}$ sensing and detection mechanisms have been studied early since 1900. The traditional mechanisms are still used widely in industry such as Gas Chromatography (GC), Mass Spectrometry (MS), Catalytic Bead (CB) and Thermal Conductivity (TC). While solid-state technologies such as semiconducting metal oxide (MOX) and Catalytic Bead (CB), need heating the catalysts to about $300^{\circ} \mathrm{C}$ to sense $\mathrm{H}_{2}$, which may be considered as an ignition source, so it is dangerous. In general, $\mathrm{CB}$ sensors are non-selective for $\mathrm{H}_{2}$. On the other hand, electrochemical sensors are based on electrolytic chemical reactions of $\mathrm{H}_{2}$ using liquid or solid electrolytes, and suffering from leakage issues. $\mathrm{H}_{2}$ sensors also based on TC, CB, MOX, and electrochemical technologies require the presence of oxygen. Within a solid-state technology, Palladium-based sensors are the most hopeful, based on sensitive and selective material for $\mathrm{H}_{2}$, palladium (Pd), not require oxygen for operation, and it is very accepted in industrial applications because of its reliability and high selectivity to $\mathrm{H}_{2}$ [17]. So it's clear that each mechanism of $\mathrm{H}_{2}$ sensing has its advantages and disadvantages and there is no specific method that can be used for sensing the leakage of hydrogen in all applications and conditions. It is very important to choose the most suitable type of sensor based on its characteristics and the environmental conditions and limits of your application. In general, any $\mathrm{H}_{2}$ sensor in order to be wide acceptable and applicable, it should satisfy the following functional parameters [13].

a) Performance: The performance of $\mathrm{H}_{2}$ sensors is mainly achieved by choosing the most suitable sensor for a specific application. $\mathrm{H}_{2}$ sensors must have a wide operating range (299\%), good sensitivity below LFL (4\% H2) in air backgrounds, fast response time, continuous operation for petrochemical applications, and operating in wet conditions sometimes (for fuel cell applications).All these characteristics should be taken into consideration while looking for the performance of $\mathrm{H}_{2}$ sensors for specific applications.

b) Lifetime: Suitable lifetime of the sensor should be related to the application and the operating costs of the sensor which should be well defined including the replacement and maintenance. For example, analytical $\mathrm{H}_{2}$ systems (GC or MS) typically used for less than ten years and required daily or weekly calibration for monitoring gases in refinery applications. While low cost in-line solid-state $\mathrm{H}_{2}$ sensor with minimal calibration is more cost effective with respect to the lifetime. For specific applications such as transportation and automotive applications, the desired lifetime is more than ten years with minimal annual calibration processes. During this lifetime, the $\mathrm{H}_{2}$ sensor should be operating properly without any cleaning procedures, frequent calibration, or replacement through operating in harsh environmental conditions.

c) Reliability: Sensors should be highly selective to $\mathrm{H}_{2}$ and have long term stability and consistent reproducibility. These are the necessary parameters to prevent any false alarms of $\mathrm{H}_{2}$ sensor. $\mathrm{H}_{2}$ sensor should also be able to resist multiple exposures to $\mathrm{H}_{2}$ concentrations without damage.

d) Cost: The cost of sensor and its controllers should be justified (purchase, installation, calibration and maintenance) versus current technology. Nowadays, a unit that costs less than $\$ 10,000$ is preferred in industrial applications for a multiple sensor technology with minimal operating costs. For automobile applications, a low-cost sensor or detector is required with minimal costs, so that replacement, maintenance and calibration less than $\$ 50$. The cost choice is usually preferred if performance, reliability, and lifetime are not compromised.

Many $\mathrm{H}_{2}$ sensors are available in the market. The challenge for new $\mathrm{H}_{2}$ sensor to be commercialized is to improve the performance and reduce the costs more than the available sensors. None of the available sensor is suitable for all applications and satisfies all the target specifications of Department of Energy (DOE). The most important requirements for a $\mathrm{H}_{2}$ sensor used in stationery and automobile application are mentioned in Table 3. The available sensors satisfy a percent of required sensitivity and selectivity, and wide range of sensor options are available, so the sensor selection is based on the application; consequently it is very important to know and understand the characteristics of given options to select 
the most appropriate one $[13,16]$. The development of hydrogen sensing technologies that can sensitively detect $\mathrm{H}_{2}$ leakage and based on the system take an action as alarming or shutting down is very important to achieve safety in $\mathrm{H}_{2}$ infrastructure. These
$\mathrm{H}_{2}$ sensors should satisfy a number of characteristics to ensure timely and appropriate responses to any leaks of $\mathrm{H}_{2}$ gas. In general, $\mathrm{H}_{2}$ sensor for safety applications should have the followings characteristics [14]:

Table 3: Most important requirements for hydrogen sensors in automotive and stationary applications.

\begin{tabular}{|c|c|c|}
\hline Parameter & Performance requirement [14] & DOE requirement [15] \\
\hline \multirow{4}{*}{ Sensitivity range } & \multirow{4}{*}{$<0.1$ to $>4 \%$} & Measuring range $0-4$ vol\% $\mathrm{H} 2$ in air; \\
\hline & & Stationary: \\
\hline & & Measuring range Up to 1 vol\% $\mathrm{H} 2$ in air (alarm limit) \\
\hline & & Lower detection limit <0.1 vol\% \\
\hline Survivability limit & $100 \%$ & $100 \%$ \\
\hline \multirow{2}{*}{ Response time } & Automotive: $<3 \mathrm{~s}$ & Automotive: Response time $\left(t_{90}\right)<3 \mathrm{~s}$ \\
\hline & Stationary: $<30 \mathrm{~s}$ & Stationary: Response time $\left(\mathrm{t}_{90}\right)<30 \mathrm{~s}$ \\
\hline \multirow{2}{*}{ Recovery time } & Automotive: $<3 \mathrm{~s}$ & Recovery time $\left(t_{10}\right)<3 \mathrm{~s}$ \\
\hline & Stationary: $<30 \mathrm{~s}$ & Recovery time $\left(\mathrm{t}_{10}\right)<30 \mathrm{~s}$ \\
\hline \multirow{2}{*}{ Temperature range } & Automotive: $-40^{\circ} \mathrm{C}$ to $+125^{\circ} \mathrm{C}$ & Ambient temperature -40 to $125^{\circ} \mathrm{C}$ \\
\hline & Stationary: $-20^{\circ} \mathrm{C}$ to $+50^{\circ} \mathrm{C}$ & \\
\hline \multirow{2}{*}{ Pressure range: } & Automotive $62-107 \mathrm{kPa}$ & - \\
\hline & Stationary: 80-110 kPa & - \\
\hline \multirow{2}{*}{$\begin{array}{l}\text { Humidity range Ambient (relative humidity } \\
\text { range) }\end{array}$} & Automotive: 0-95\% & \multirow{2}{*}{ Ambient humidity: 0-100\% relative humidity } \\
\hline & Stationary: $20-80 \%$ & \\
\hline Power consumption & $<1 \mathrm{~W}$ & - \\
\hline \multirow{2}{*}{ Lifetime } & Automotive: $6000 \mathrm{~h}$ & \multirow{2}{*}{ Durability/lifetime: $3-5$ years } \\
\hline & Stationary: $>5$ years & \\
\hline Accuracy and & Automotive: $5-10 \%$ & \multirow{2}{*}{ Accuracy: 10\% } \\
\hline repeatability & Stationary: $10 \%$ & \\
\hline
\end{tabular}

i. High sensitivity.

ii. Fast response.

iii. Wide dynamic range.

iv. High selectivity and immunity to common interferences (such as humidity and existence of other gases).

v. The sensor must be very stable.

vi. Long lifetime with acceptable low false positive responses.

vii. Operation near room temperatures.

viii. For widespread commercial acceptance sensors, low cost sensor networks are essential.

\section{Traditional Principles for Hydrogen Sensing}

Thermal conductivity is the most extended measuring principle for $\mathrm{H}_{2}$ and then GC (Gas chromatography) is the second most applied principle for $\mathrm{H}_{2}$ detection. The length of response time in minutes is the main disadvantage of GC, sample preparation time, consumable gases (carrier and calibration gases), and intensive labor handling procedures. On the other hand, it has the advantage of having the ability to measure other gases, such as oxygen, nitrogen, and carbon dioxide in the presence of $\mathrm{H}_{2}$, which adds time to the analysis process. MS (mass spectrometer) is another technology which is widely used for $\mathrm{H}_{2}$ sensing and detection in the industry [18]. Process MS such as GC must be safety certified. MS requires special shelters for air-conditioned, safety monitors, many gases for calibration (e.g., fragmentation gases), and frequent maintenance (weekly) by a skilled operator, Similar to GC, the MS also requires extensive sample systems and continuous flow for sample gases that add cost and make it more complex to carry out.

A laser gas analyzer based on laser light which absorbed by $\mathrm{H}_{2}$ and remits it at a different frequency. Which is caused "Raman shift" frequency of the light re-emitted. The shifts are discrete and precise such as the intensity of light at different frequencies is directly proportional to the concentration of $\mathrm{H}_{2}$. These instruments are very expensive, around $\$ 100,000$ and more.

\section{Main Types of Hydrogen Sensors}

Several types of hydrogen sensors working by different mechanisms become available recently, most of them use palladium to hold $\mathrm{H}_{2}$. A reliable sensor should have some characteristics such as high sensitivity, linear response in wide range of concentrations, good stability, and low response and recovery times [19]. Another critical factor to be considered is Low power consumption. 
Selecting a proper material is the first step in order to achieve these characteristics and reach high performance. In addition, morphology, structure, and chemical composition have a significant role on the operation of this material. Moreover, one of the most common disadvantages of these sensors is reliability degradation due to aging factors. For example, many changes can occur in Pdsemiconductor sensors that are exposed to room air such as loss of sensitivity, with a lengthened response time. Aging can also change particle morphology, chemical composition and interfacial structure. Aging depends basically on the environmental storage, operating conditions and on how well the sensor materials are isolated from the environment [20].

L Boon Brett et al. [15] presented performance tests of hydrogen sensors. A total of seven different performance assessment tests were carried out on 39 commercially available sensors employing either catalytic, electrochemical, metal-oxide semiconductor or thermal conductivity detection principles [21]. L. Boon-Brett et al. also summarize the current state of the market with respect to hydrogen sensing technologies and identify disparities between existing performance targets for hydrogen safety sensors and the actual performance specifications given for commercially available sensors, with the intention that this should then help to direct future research and development in the area [15].

\section{Electrochemical Sensors}

Electrochemical sensors (EC), detect $\mathrm{H}_{2}$ depending on a specific electrochemical reaction between the cathode and the anode $[22,23]$, hydrogen is oxidized on the surface of an electrode coated with a catalyst, such as platinum [24]. The resulting electrical signal is either a current or a voltage correlated to the concentration of $\mathrm{H} 2$ which can be correlated by a nonlinear relationship with the concentration. Usually the reaction at the cathode is the reduction of oxygen, which must be present for correct operation of this type of sensors. Amperometric or potentiometric sensors [25,26], which based on electrochemical reaction produces an electrical current/ voltage proportional to the concentration of the target gas, by oxidation process which includes the electrons transfer between the electrode and the molecule. A porous membrane which is a gas barrier of diffusion is incorporated at the gas-electrode interface so that the process is controlled by diffusion as shown in Figure 1 resulting in an electrical current proportional to gas concentration.

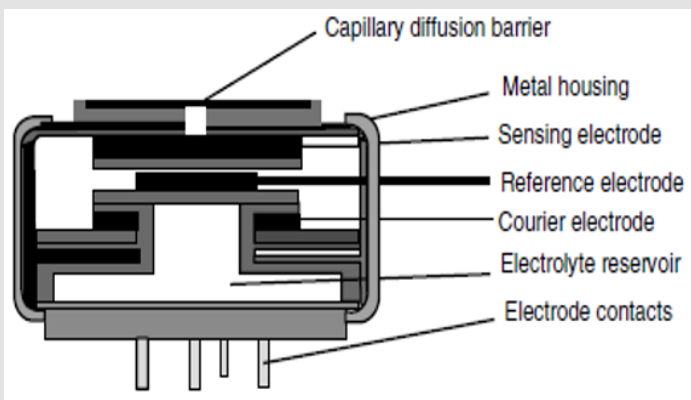

Figure 1: Electrochemical sensor with membrane for gas transport, and metal housing to prevent electrolyte leakage [15].
Amperometry devices are commercially available from many manufacturers, they are small, and have good sensitivity and a broad linear range [1]. The sensors are stable with lifetimes of up to two years, which is significantly less than the DOE target of 10 years. Limitations include a restricted temperature range due to a liquid electrolyte, moderate selectivity (e.g., CO can affect the sensor), and a dependence on environmental pressure. Electrochemical sensors have a high sensitivity to hydrogen and consume very little power in operation which is very useful in some applications such as automobile applications. The sensitivity of electrochemical sensors decreases with time mainly due to deterioration of the electrode catalyst [15].

Metal - Oxide Sensors: Metal Oxide (MOX) sensors are fabricated with a wide band gap semiconductor material; The MOX sensor is a small, readily produced device and has sufficient sensitivity for hydrogen safety application [27]. MOX sensor is not affected by ambient temperature variations. The MOX sensor is not considered as a selective device [21], a cross sensitivity problems, such as Moisture variations which can also affect the calibration curve of MOX. The response of the classic MOX sensor was not linear. a long response time and even longer recovery time is another disadvantage of classic MOX [28-31]. Figure 2 shows the schematic diagram of MOX sensor [3]. The performance of a MOX sensor can be permanently corrupted when exposed to certain silicon compounds (which may include common industrial sealants and lubricants) [32-40].

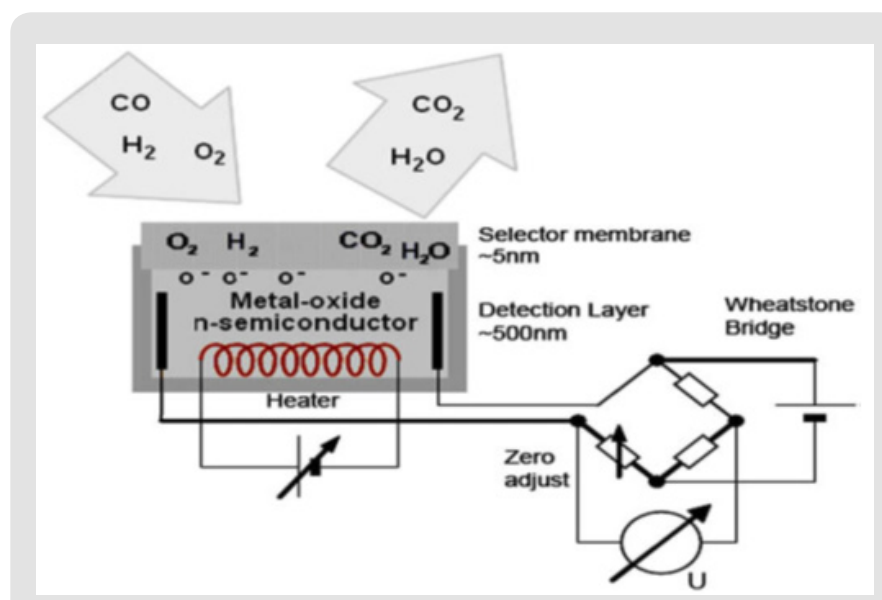

Figure 2: Schematic of a MOX type chemical sensor [89].

These sensors typically need oxygen for stable responses and should not been widely applied to process streams or very high concentrations of $\mathrm{H}_{2}$ [41], thus these devices cannot be readily installed in a nitrogen-purged environment. The reliability of these thin-film designs in relation to environmental parameters such as pressure, relative humidity (RH), selectivity, and long-term stability must be further investigated. Metal-Oxide Semiconductor (MOS) as a type of MOX sensors consists of three layers: a metal layer, an insulator layers, and a semiconductor layer. Mostly the insulating layer is formed by an oxide (0) leading to be called MOS [42,43]. This class of sensor works on the principle of charge building and 
changing of the function of the active layer, which is usually a noble metal or noble metal alloy, e.g. palladium-based alloys. This MOS structure may work as a capacitive sensor, a MOSFET transistor or a Schottky diode [44-48]. This type of technology can operate in the absence of oxygen. The acronym MOS is often used in the literature and by sensor manufacturers to describe both the triple layer metal-oxide semiconductor sensor. MOX are under intensive development and have been studied extensively for decades for many reasons, such as simple structure, small size, low cost and high sensitivity with fast response. In these sensors, the response of thin layer in contact with a target gas would be changing in its resistance [49].

J Huang et al. [37] studied the Hydrogen sensing characteristics of Pd-based Schottky diodes sensors with different hydrogen concentrations and compared the result over a wide temperature operating range. Experimentally, when exposed to hydrogencontaining gases, both Schottky-type hydrogen sensors can be operated under bi-polarity applied voltages. Upon hydrogen adsorption, Schottky diodes manifested faster adsorption and desorption responses at higher temperatures ( $\geq 400 \mathrm{~K}$ ) [50]. J Jun et al. [39], design a hydrogen detecting system consisting of solar and vibration energy harvesting devices, $\mathrm{ZnO}$ nanorod-based sensor, sensor interface, microcontroller, and the RF front end of our sensor system was designed and fabricated. The system could detect the presence of hydrogen and transmitting the detected data wireless for monitoring, while obtaining the necessary power for operation through energy scavenging devices. B Lyson et al. [36], studied the gas sensing properties of nano-crystalline $\mathrm{TiO}_{2}$ : $\mathrm{Cr}$ nano-powders obtained by Flame Spray Synthesis (FSS). This method was used because it allowed us to obtain crystalline powders in a single step.

C Hsu et al. [51], developed and investigated an interesting transistor-based hydrogen detection system, Experimentally. And they found that even at a low hydrogen concentration, the studied sensor still has a high sensitivity at room temperature. Also, a simple hydrogen sensing system with a LED array (light emitting diode) and buzzer is designed and established. The proposed system could display and alarm the hydrogen concentration quickly. Based on a micro-controller, the studied hydrogen sensing system is shown to be of low cost, fast response, portable, and easy operations.

Catalytic Gas Sensors (Cgs): Catalytic sensors consist of two thin platinum wires each embedded in a ceramic bead (pellistor) and connected to each other in a Wheatstone bridge [52-54]. One pellistor is coated with a catalyst material which selectively catalyses the oxidation of hydrogen as shown in Figure 3. The pellistors are heated to around $500-550^{\circ} \mathrm{C}$ and hydrogen is oxidized on the active bead surface causing an increase in temperature and an increase in the resistance of the platinum filament. The resulting imbalance of the Wheatstone bridge is linearly related to the hydrogen concentration. Catalytic sensors employ a well-developed technology but are not specific to hydrogen and will respond to any combustible gas. Also, presence of oxygen is essential to their operation. Heated ceramics embedded with platinum or other noble metal as a catalyst provide a catalytic surface for hydrogen in air combustion. The sensor often is called a pellistor sensor. The device is heated electrically to approximately $550^{\circ} \mathrm{C}$. The coated surface catalyzes combustion when exposed to hydrogen or other combustible vapors. The catalyzed combustion is localized to the surface of the sensor and increases the temperature of the device. A thin platinum wire is encapsulated within the ceramic bead. Because the resistance of any material is affected by temperature, the surface combustion changes the resistance of the internal platinum wire. For improved stability, the Combustible Gas Sensor (CGS) often is referenced to a second nearly identical but catalytically inactive bead; both the active and inactive elements often are integrated into a single housing. The CGS routinely is used for $0-10 \%$ hydrogen in air, and these sensors have been used for more than 20 years in confined space a safety applications. The CGS essentially is used for the detection of combustible vapors (especially in the petroleum industry).

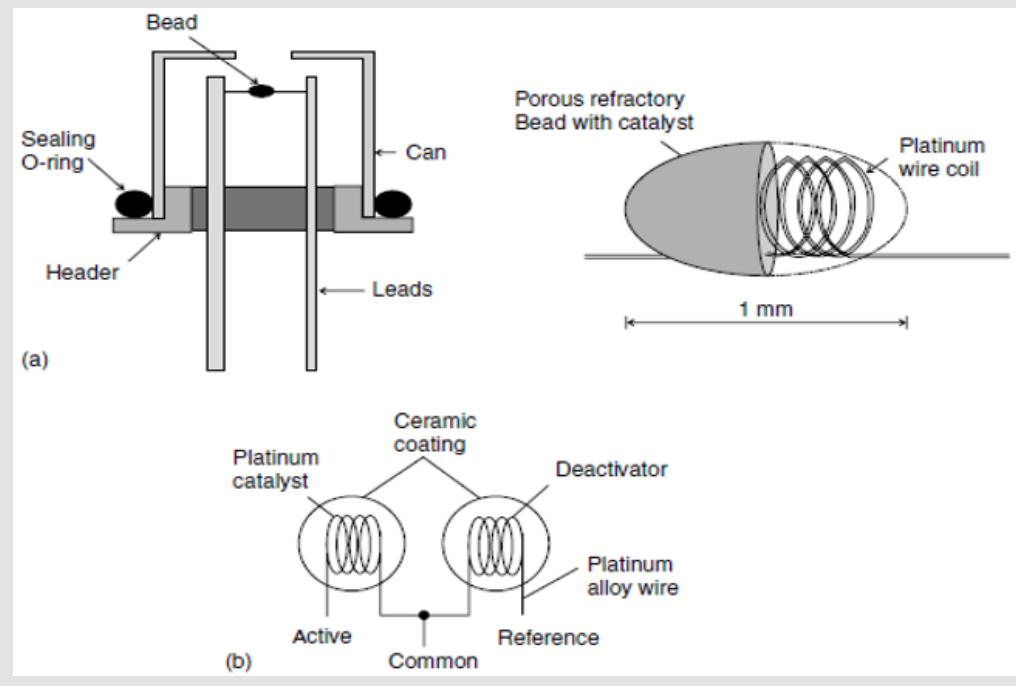

Figure 3: CGS technology and (b) CGS configuration [100]. 
The pellistor, however, is not selective and cannot differentiate between different combustible gases. Of course, the nature of the application could be such that only one combustible gas is required, and thus imperfect selectivity is not always a relevant issue. Conversely, some applications could have numerous possible combustibles present, for example at a mixed hydrogen gasoline fueling station. Fundamentally, these devices will not function without oxygen since oxygen is essential for any combustion process. Furthermore, the high operating temperature of the CGS requires significant electrical power for operation. As with other solid-state sensors, improvements in power requirements and response times are possible with miniaturized thin-film structures that utilize Modern Micro-Electromechanical Systems (MEMS) technology for fabrication [16].

Thermal Conductivity Sensors: Thermal conductivity (TC) sensors [55] based on a temperature change of an electrically heated sensing element following exposure to a specific gas as shown in Figure 4. The TC sensor is not heated to a temperature that induces combustion, but only to a temperature where the resistance of the sensing element deviates from the linear limit of Ohm's law ( $\mathrm{V}=\mathrm{I} \times \mathrm{R}$ ). This is illustrated in a voltage-current plot of the TC device. A thin probe element is used in the TC sensor [56]; a linear increase in current is observed as a low voltage is applied to the sensing element. In an I-V plot the slope of the linear region is the reciprocal resistance $(1 / R)$ of the element. As the applied electrical power (I-V) increases, the ability to dissipate heat to the surrounding environment (air matrix) is exceeded, resulting in increasing the temperature of the probe element. The resistance no longer remains constant and a deviation from a linear I-V plot is observed. In addition to the input power, which is controlled by the TC control circuit, the thermal conductivity of the surrounding gas affects the shape of the I-V curve [57-60].

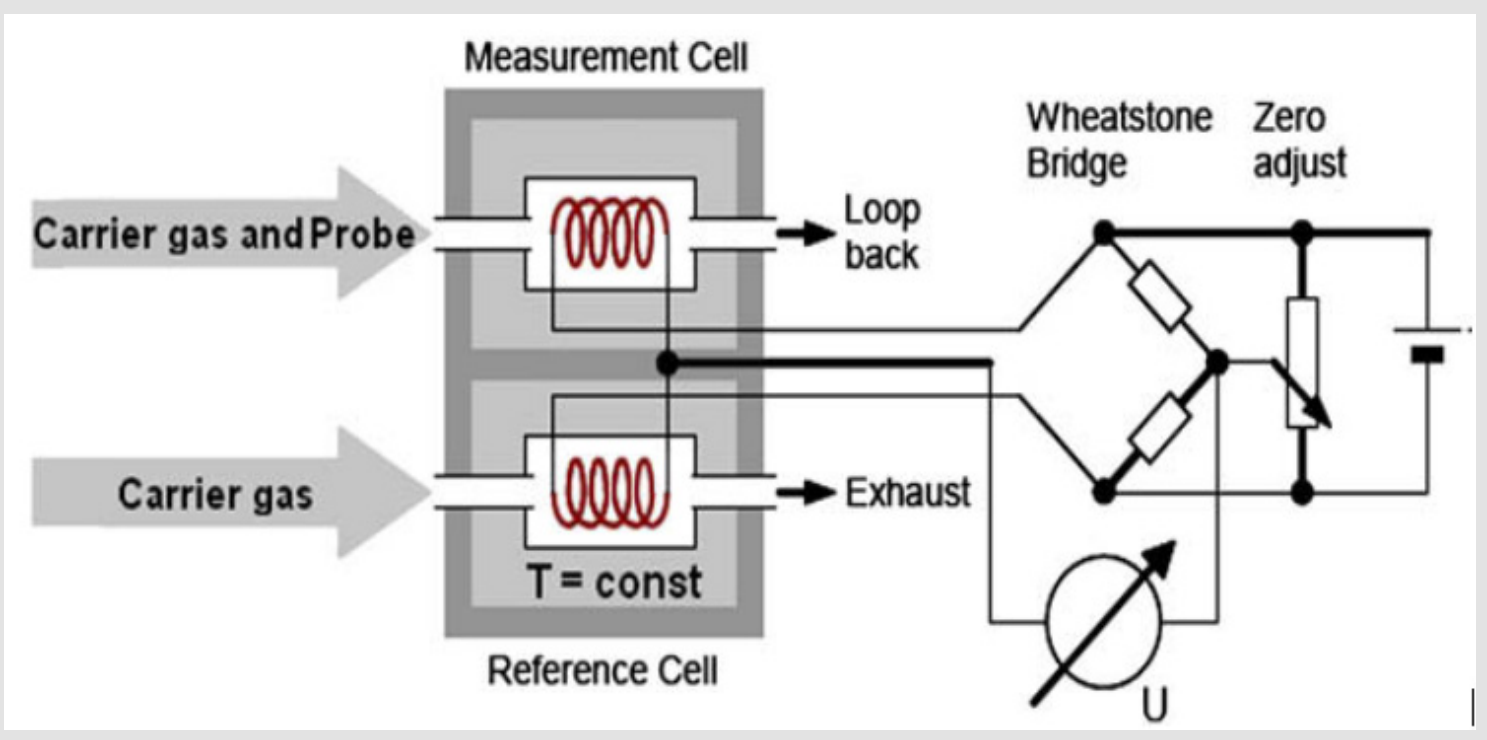

Figure 4: Schematic of a thermal conductivity type sensor [89].

Some manufacturers claim a $0-100 \%$ range for hydrogen; more recently, devices for lower concentration ranges relevant to safety have appeared on the market. Thermal conductivity sensors are stable devices; they are less liable to contamination. They tend to be non-selective, but by using special coatings vendors have reported improved selectivity. Since thermal transport between a solid and a gas will be dependent on the temperature, density, and composition of the gas, these sensors are affected by environmental parameters such as temperature, pressure and humidity. As with many technologies the environmental effects can be compensated, but this requires independent measurement for ambient conditions. Operation of a TC sensor requires less power than that required for catalytic combustion. The TC sensor is applicable in MEMS technology [61,62], which reduces the power requirements. Also results in rapid response times less than second. Unlike almost other sensor platform, the TC sensor does not require oxygen for stable and long-term operation. So it can be use in process streams or applications which use nitrogen purging. Modern TC sensors have a simple design without using a reference cell. The detection is based on the heat lost to the test gas with a reference point being set under defined conditions in the absence of target gas (hydrogen). TC hydrogen sensors are less sensitive, but offer a measuring range up to $100 \%$ hydrogen and are not liable for poisoning like other hydrogen sensor types.

\section{Optical Sensors}

Sensors for the directopticaldetection of hydrogen are notreadily available because hydrogen is non-adsorbing in the ultravioletvisible or infrared [63]. However, very sensitive sensor platforms which undergo changes in optical properties upon exposure to hydrogen have been developed. Many devices are based on optical properties of palladium films. Other devices are based on chemical 
mediators that undergo color changes upon exposure to $\mathrm{H}_{2}$. Two main classes of chemically mediated optical hydrogen sensors have been developed, fiber optic based devices and a recently developed colorimetric indicator. The sensor tip is coated with several layers of material, including a hydrogen-sensitive chemical (tungsten or molybdenum oxide) that undergoes a color change when exposed to hydrogen. The colorimetric agent is very selective to hydrogen. Also the tip is coated with a hydrogen-permeable protection layer to protect the sensor from chemical poisons. As with all fiber optics systems, remote operation is achieved.

These sensors also have a good sensitivity to hydrogen, simple operating mechanism, long-term stability, and reversibility where oxygen is required. Conversely, the response time is relatively slow, and although the sensor provides quantitative data, its accuracy is less than the DOE targets. Several fiber optic sensors based on palladium films also have been developed, but many of them are not yet commercially available. Colorimetric indicators are being developed for hydrogen. Such systems do not require electronic circuitry for detection. The indicator also can be incorporated into an electronic platform, however. These systems are passive and undergo a spontaneous color change when exposed to hydrogen. Reversible and irreversible formulations have been developed. The active material can be incorporated easily into a low-cost $\mathrm{H}_{2}$ indicating paint. The material is stable environmentally and its process is not affected by temperature, pressure, or relative humidity significantly. This system is low cost and easily implemented; though, quantization is not achieved [64-67]. The usage of electricity in presence of hydrogen is always a matter of concern taking into account possible arcing. With such limitations and possible hazards for other detection techniques, optical sensor has gained importance in safety applications [68].

\section{Palladium Film and Palladium-Alloy Films}

The unique and highly selective permeability of hydrogen into Palladium (Pd) has led to Pd-film technology to be applied to several types of $\mathrm{H}_{2}$ sensors. One basic technology is the Pd film and Pd alloy films $[69,70]$. The film resistance changes with adsorption of hydrogen, and this resistance can be monitored as in chemical sensors. Such devices have the advantage of a very simple processing signal. Alternatively, thin Pd films have been integrated into Field Effect Transistor devices (FET) where the gate is palladium and the performance of the transistor is controlled by the changes in the gate resistivity [71,72]. F Razi et al. [20] investigated a porous silicon (PS) based sensors, where non-oxidized samples show high sensitivity only for fresh samples which decreases according to the age of the sensor. $\mathrm{H}_{2}$ sensing properties and changes of these samples by aging were measured at room temperature. So, the morphology, structure and chemical composition of Pd-Porous silicon samples were investigated and their effects on the hydrogen sensing properties were discussed.

Major classes of Pd based $\mathrm{H}_{2}$ sensors [73]. a) Palladium resistors sensor (most popular). A thin Pd film deposited between two contacts shows a change in conductivity when exposure to $\mathrm{H}_{2}$ gas.

b) The palladium field effect transistors (FETs) or capacitor sensor, where the sensor is in a transistor or capacitor configuration.

c) Palladium optical sensors, consisting of optical active material coated by a layer of Pd, transforms the concentration of H2 to an optical signal [64].

d) Palladium Meso-wire (nanowire) and nano-particle sensors [74].

e) Palladium Nanotube and Nano-clusters sensors [75]

Palladium films also can be applied to other sensor types, for example coating mechanical devices such as Surface Acoustic Wave sensor (SAW) or Quartz Crystal Microbalance sensor (QCM) to achieve good selectivity. Basically, adsorption of $\mathrm{H}_{2}$ changes the mass of the Pd film so changes the resonant frequency of the mechanical sensor. Small shift in frequency can be accurately measured, so it is excellent for detection lower limit [76,77].

On the other hand, Pd-film devices have bad performance under anaerobic conditions, because of Pd phase change that needs oxygen in the air to improve its reversibility. Pd films also are liable to chemical poisoning, mainly by sulfide. Several vendors minimized sulfur and other possible poisons effects by using a protective, $\mathrm{H}_{2}$ permeable and sulfur impermeable coating over the Pd film. In many environments, the long-term stability of the coating is not fully characterized, but some vendors have been reported good performance. The normal devices have slow response time more than 30s, comparing to TC sensors and some of the new thin film sensors. However, newer Pd sensors on a MEMS platform have a faster response time.

Combined Technology Sensors: Combined sensor (COMB) is a combination of different detection technologies in one sensor [78], such as, catalytic and thermal conductivity. So, it may have the added advantage of measuring hydrogen concentrations over a wide range. The oxygen requirement of such sensors depends on the contents of sensor types [79-82]. Fasaki et al. [38] modifying $\mathrm{SnO}_{2}$ sensor with $\mathrm{Au}$ nanoparticles which decreases the working temperature from 180 to $85^{\circ} \mathrm{C}$, while the response increased almost by 50 times, and can detects $\mathrm{H}_{2}$ concentration as low as 500 ppm. S Kim et al. [83] also realized a multiple-networked GaN nanowires with excellent sensing properties by functionalizing their surfaces with Ga2Pd5 nanodots. Compared to the bare nano-wire sensors, the relative resistance responses improved by a factor of $>50$ at $\mathrm{H}_{2}$ concentrations from 100 to $2000 \mathrm{ppm}$. While Sh. Tan et al. [84] investigated a GaN-based Hydrogen sensor with a Pd-base mixture. A rough surface observed for the Pd-mixture deposited by thermal evaporator (Pd metal and $\mathrm{SiO}_{2}$ dielectric). And Pd nanoparticles 
formed by wet etching method over interlayer. Comparisons between the sensors with the deposited Pd-mixture and wet-etched Pd layer were addressed. Also B. Huang and T Lin [85] created a novel type of hydrogen sensor based on using a nano-composite plating technique, enhancing the sensing performance and the sensitivity. So combining the nano-material to the old techniques improves the performance of the sensors, as a result most of the research and developments are under these types of sensors.

\section{Applications of Hydrogen Sensors}

\section{Hydrogen Fueling Stations}

Hydrogen is odorless comparing to the gasoline fume, adding substrate to $\mathrm{H}_{2}$ causing an odor has been already patented. But such additives can be harmful to fuel cells. This critical area of research helps the user to detect $\mathrm{H}_{2}$ leakage before the explosive limits. The automotive industry should have a safe operating system so the users are not scared to try these new vehicles [86]. The need for $\mathrm{H}_{2}$ safety sensors has been reviewed by the automotive industry and the DOE of U.S. The suggested number of sensors is from 2-6 sensors per vehicle. These sensors have different operating environments, but if one type of sensor can meet all environments the cost of sensores per vehicle will minimized, and the operational cost can be better controlled. Each hydrogen sensor is independently coupled to the controller and can be used to shut down a hydrogen fuel port. For example, a fueling nozzle forms a part of a monitoring and control system and positioning the $\mathrm{H}_{2}$ sensor inside the nozzle housing allows the monitoring of $\mathrm{H}_{2}$. Such hydrogen sensors must be reliable, specific, and sensitive. They should be also able to respond quickly to $>0.2 \% \mathrm{H}_{2}$, and they must be not affected by the environmental parameters (temperatures from $-10^{\circ} \mathrm{C}$ to $+50^{\circ} \mathrm{C}$, $\mathrm{RH}$ ) and must have long lifetime with stable behavior more than 12 months.

\section{Hydrogen Pipelines}

Hydrogen delivery pipelines include transmission and distribution pipelines. In conventional terminology, transmission lines use relatively large-diameter and high-pressure pipelines (35-100 bar). In contrast, distribution lines typically deliver small volumes through smaller-diameter and lower pressure pipelines (0.3-14 bar). For hydrogen delivery, pressures in distribution lines are likely to be higher (14-28 bar) compared with NG. Sometimes, hydrogen will be mixed with NG for transport, and separated by membrane technology at the point of use. Pipeline safety is one issue; the other is to determine the $\mathrm{H}_{2}$ content within the pipeline. This would take advantage of the current NG pipeline infrastructure and reduces the costs. In this case, hydrogen sensors would be placed inside the pipeline to monitor the $\mathrm{H}_{2}$ concentration.

\section{Cryogenic Hydrogen Storage Tanks}

Nowadays in the U.S, there are 10 facilities for liquid $\mathrm{H}_{2}$ produce 5,400 to $32,000 \mathrm{~kg} /$ day. All of them are managed by the gas produc- ers. Also, the transportation of liquid $\mathrm{H} 2$ is limited by distance and roadway access as defined by the U.S. Department of Transportation. Liquid hydrogen with the highest purity has a limited market such as electronics, specialty stainless steel and fuel cell researches and developments. Storage of liquid hydrogen is achieved in large insulated tanks from which are dispensed to liquid tankers for transport. Usually, hydrogen sensors (mostly flammable sensors) are used in and around such facilities. As hydrogen sensors and solid-state sensors become more reliable, and if their cost is reduced they will replace the common flammable gas sensors. Such storage tanks are constantly boiling-off $\mathrm{H}_{2}$, otherwise the pressure within the tank will rise well above the nominal 10-15 psig. Therefore, the uses of accurate and precise hydrogen sensors to report the changing partial pressure are very important.

\section{Hydrogen Fuel Cells and Automobiles}

Hydrogen is used as a fuel in Proton Exchange Membrane (PEM) fuel cells in concentrations of $60-100 \%$. The hydrogen is converted into water and electrons through a proton exchange process at the polymer membrane. Hydrogen fuel cells as a power source are used in automotive and can be used as backup for generators and small power plants. Hydrogen is a clean fuel compared to NG because it has lower emissions. While, to used hydrogen in an automobile or in a generator room it has to be accurately monitored to prevent the risks of explosion. The hydrogen sensor installed in the anode loop of the fuel cell should not have a response delay time or affected by water vapor. The emissions from fuel oxidant outlet of a fuel cell has also to be monitored to prevent possible explosions as the concentration of hydrogen is in the range $0-4 \% \mathrm{H}_{2}$ at oxygen-reduced mixture. Hydrogen leak sensor is also required in the fuel cell ventilation areas [75]. An accurate leak detector should be able to detect $0-4 \% \mathrm{H}_{2}$ in air backgrounds without any cross-sensitivity to other gases such as, methane $\left(\mathrm{CH}_{4}\right)$, carbon monoxide (CO), carbon dioxide $\left(\mathrm{CO}_{2}\right)$, and nitrous oxides $\left(\mathrm{NO}, \mathrm{NO}_{2}\right)$.

The major requirement for a reliable hydrogen sensor in the fuel cell environment is to hold up 100\% condensing humidity. Most of the fuel cells have rich humidity environment and the sensor needs to operate continuously in this environment. In some cases, the $\mathrm{H}_{2}$ sensor can also be operated at very low temperatures (as low as $-40^{\circ} \mathrm{C}$ ). So, the sensor also needs to reach ambient temperature quickly ( $<30$ second) and continue operation well below ambient temperature. And because the gas mileage is very important, the unused hydrogen in such vehicle is re-circulated. Other safety action is to monitor $\mathrm{H}_{2}$ leakage in garages also to ensure that there is no leak from $\mathrm{H}_{2}$ vehicle, as well as the passenger compartment to ensure the safety of passengers.

Most solid-state sensors are heated to above $100^{\circ} \mathrm{C}$ and can operate in the "cold start" condition in a fuel cell. Another important performance parameter for a hydrogen sensor in a fuel cell is its resistance to water. Most fuel cells have excess of liquids including water during operation. It is highly possible that water will splatter 
or go through into hydrogen sensor of a fuel cell. Usually, hydrophobic membranes are used in hydrogen sensors to prevent water entry into the sensors. Recent developments in solid-state hydrogen sensors and inorganic coating technologies at molecular level enable gas sensor to operate without interference from high relative humidity and condensing water. Also, for fuel cell applications, hydrogen sensors need to operate in a wide temperature range $(-40$ $-100^{\circ} \mathrm{C}$ ) and should have fast response times.

\section{Hydrogen Safety and Control}

Safety is considered as one of the most significant issues that the promotion of hydrogen use has to face. More utilization of hydrogen fuel will increase the possibility of accidents in the $\mathrm{H}_{2}$ facilities or infrastructure. Therefore, various safety issues have been discussed in the use and handling of $\mathrm{H}_{2}$. These issues include hydrogen permeation, embrittlement, leakage, ignition and explosion. Research on $\mathrm{H}_{2}$ leakage is mainly important for preventing accidents and setting safety guidelines and standards for hydrogen usage due to embrittlement, bad sealing, human errors and/or system degradation. So, to ensure the safety in this field, the development of risk management plane or strategies for $\mathrm{H}_{2}$ leakage is required. As the sensing of $\mathrm{H}_{2}$ is very important in this system as discussed previously, the control system and actuators that take the decision to do suitable action to the risk level based on the measured $\mathrm{H}_{2}$ concentration and environmental conditions are also significant parts in such system.

Recently, a lot of researchers are focusing on issues related for hydrogen leakage. These include a liquid $\mathrm{H} 2$ jet flow through a nozzle [90], transient distribution in a vertical cylinder [91], as well as ventilation and dispersion in a garage [92,93], a tunnel [94], and a domestic room [95]. As found in these studies, hydrogen distribution and accumulation in highly confined spaces are very dangerous. Regardless of the little guidance of risk developed for such scenarios. For this circumstance, Matsuura et al. [96] proposed ways of reducing the risk by changing the vent positions, conditions and its relationship with the outside environment, and how this affects the distribution of $\mathrm{H}_{2}$. Matsuura et al. [96] proposed an innovative adaptive algorithm for sensing leakage of $\mathrm{H}_{2}$ in a partially open space. Matsuura [96] also observed the effects of ventilation system on $\mathrm{H}_{2}$ distributed and accumulation based on natural ventilation (NV) and forced ventilation (FV). Usually $\mathrm{FV}$ is expected to be more rapid than NV. However, using NV or FV depending on the geometrical configuration of a ventilated space [96], the sensing algorithm was proposed for NV only [96]. Other actions were taken place mainly in storage facilities of $\mathrm{H}_{2}$ or fuel cell vehicles is shutting down the supply system by using controllable valve on $\mathrm{H}_{2}$ cylinders.

\section{Conclusion}

The accurate hydrogen detection is critical requirement in several industries for everyday safety and process improvement because of the growing needs for hydrogen fuel. And from this review work the main points to be concluded are:

a) The user should carefully consider the application and environmental parameters before selecting an optimum hydrogen sensor. Real-time and in-line $\mathrm{H}_{2}$ sensors are in immediate need for the process industry as alternative to analytical instruments such as gas chromatography.

b) $\mathrm{H}_{2}$ sensitivity and selectivity is very important to prevent false alarms for almost any applications.

c) There is several technologies that have been developed and manufactured for the detection of hydrogen gas. Just some of these are well-established commercially and for years.

d) Hydrogen sensors will be widely used in the next 5-10 years due to the advantages of hydrogen economy and its related infrastructure.

e) The palladium-based hydrogen sensors are the most extensively researched and hold the most promise for the industry. Also, fiber optic-based technology, MEMS (micromachined mechanical system), and nano-technology sensors for the measurement of hydrogen are ongoing research to impose new performance requirements such as faster response, lower power consumption, high selectivity and critical operating conditions.

f) Hydrogen sensors will find applications in industry such as, petrochemical plants, petroleum refineries, hydrogen production facilities, nuclear power plants, fuel cells, leak detection, medical diagnostics, and other applications.

g) When designing a system or facilities that use hydrogen, it's very important to take into consideration natural ventilation and/or forced ventilation to reduce the risk of $\mathrm{H}_{2}$ accumulation and ignition or explosion as well as automatic controlled detection system for leakage.

h) The most common control actions that take place when hydrogen leakage happens is shutting down the source of hydrogen and activate forced ventilation system automatically.

\section{References}

1. Vivek PU, Todd T (2005) Safety of compressed hydrogen fuel tanks: Leakage from stationary vehicles. Technology in Society 27: 315-320.

2. Mami Y, Sri A, Yuki F, Michael B, Vladimir V, et al. (2012) Selective hydrogen detection at high temperature by using yttria-stabilized zirconia-based sensor with coupled metal-oxide-based sensing electrodes. Electrochimica Acta 76: 152-158.

3. Soundarrajan P, Schweighardt F (2008) Hydrogen Sensing and Detection. In: Ram B. Gupta editor. Hydrogen Fuel: Production, Transport, and Storage. Alabama: CRC Press 624

4. El Amin MF, Sun S (2012) Horizontal H2-air turbulent buoyant jet resulting from hydrogen leakage. International Journal of Hydrogen Energy 37(4):3949-3957.

5. Isaac W, Erik GM, Daniel ED, Mark AG (2011) Performance-based testing for hydrogen leakage into passenger vehicle compartments. International Journal of Hydrogen Energy 36(16): 10169-10178. 
6. Gabriele L, Alessandro T, Valerio C (2008) Inherent safety key performance indicators for hydrogen storage systems. Journal of Hazardous Materials 159(2-3): 554-566.

7. Ramamurthi, Karnam B, Srinivasa M (2009) Formation of flammable hydrogen-air clouds from hydrogen leakage. International Journal of Hydrogen Energy 34(19): 8428-8437.

8. Vudumu S, Koylu U (2009) Detailed simulations of the transient hydrogen mixing, leakage and flammability in air in simple geometries. International Journal of Hydrogen Energy 34(6): 2824-2833.

9. Mark R, Deborah Wi (2011) The safety of the future hydrogen economy Process. Safety and Environmental Protection 89(6): 452-462.

10. Salva J, Tapia E, Iranzo A, Pino F, Cabrera J, et al. (2012) Safety study of a hydrogen leak in a fuel cell vehicle using computational fluid dynamics. International Journal of Hydrogen Energy 37(6): 5299-5306.

11. Najjar Y (2013) Review- Hydrogen safety: The road toward green technology. International Journal of Hydrogen Energy 38(25): 1071610728.

12. $\mathrm{Ng} \mathrm{H}$, Lee J (2008) Comments on explosion problems for hydrogen safety. Journal of Loss Prevention in the Process Industries 21(2): 136-146.

13. Praveen K, Sekhar P, Eric L, Brosha E, Mukundan R, et al. (2012) Packaging and testing of a hydrogen safety sensor prototype. International Journal of Hydrogen Energy 37(19): 14707-14713.

14. Pattona J, Hunterb S, Sepaniaka M, Daskosa P, Smith D (2010) Rapid response micro-sensor for hydrogen detection using nanostructured palladium films. Sensors and Actuators A Physical 163(2): 464-470.

15. Boon Brett L, Bousek J, Black G, Moretto P, Castello P, et al. (2010) Identifying performance gaps in hydrogen safety sensor technology for automotive and stationary applications. International Journal of Hydrogen Energy 35(1): 373-384.

16. Buttner W, Post M, Burgess R, Rivkin C (2011) An overview of hydrogen safety sensors and requirements. International Journal of Hydrogen Energy 36(3): 2462-2470.

17. Hubert T, Boon Brett L, Black G, Banach U (2011) Hydrogen sensors-A review. Sensors and Actuators B 157(2): 329-352.

18. Malcolm A et al. (2010) Miniature mass spectrometer system based on a micro-engineered quadrupole filter. Analytical Chemistry 82(5): 17511758.

19. Boon-Brett L, Black G, Moretto P, Bousek J (2010) A comparison of test methods for the measurement of hydrogen sensor response and recovery times. International Journal of Hydrogen Energy 35(14): 76527663.

20. Razia F, zada A, Rahimia F (2010) Investigation of hydrogen sensing properties and aging effects of Schottky like Pd/porous Si. Sensors and Actuators B 146(1): 53-60.

21. Wanga Z, Hua Y, Wanga W, Zhang X, Wanga B, et al. (2012) Fast and highlysensitive hydrogen sensing of $\mathrm{Nb205}$ nanowires at room temperature. International Journal of Hydrogen Energy 37(5): 4526-4532.

22. Schwandt C, Frey D (2000) Hydrogen sensing in molten aluminum using a commercial electrochemical sensor. Ionics 6(3-4): 222-229.

23. Hulanicki A, Glab S, Ingman F (1991) Chemical sensors definitions and classification. Pure and Applied Chemistry 63(9): 1247-1250.

24. Sekhar P, Brosha E, Mukundan R, Nelson M, Williamson T, et al. (2010) Development and testing of a miniaturized hydrogen safety sensor prototype. Sensors and Actuators B 148(2): 469-477.

25. L Dai, Wang L, Sha G, Li Y (2012) A novel ampere-metric hydrogen sensor based on nano-structured $\mathrm{ZnO}$ sensing electrode and CaZr0.9In0.103-1 electrolyte. Sensors and Actuators B 173: 85-92.

26. Kumar P, Malhotra L (2004) Palladium capped samarium thin films as potential hydrogen sensors. Materials Chemistry and Physics 88(1) 106-109.
27. Katsuki A, Fukui $\mathrm{K}(1998) \mathrm{H}_{2}$ selective gas sensor based on $\mathrm{SnO}_{2}$. Sensors and Actuators B 52(1-2): 30-37.

28. Hung S, Chang C, HsuC, Chu B, Lo C, Pearton S, Holzworth M, et al. (2012) $\mathrm{SnO}_{2}$ functionalized $\mathrm{AlGaN} / \mathrm{GaN}$ high electron mobility transistor for hydrogen sensing applications. International Journal of Hydrogen Energy 37(18): 13783-13788.

29. F Greco, Ventrelli L, Dario P, Mazzolai B, Mattoli V (2012) Micro-wrinkled palladium surface for hydrogen sensing and switched detection of lower flammability limit. International Journal of Hydrogen Energy 37(22): 17529-17539.

30. Yamaguchi M, Anggraini S, Fujio Y, Sato T, Breedon M, et al. (2013) Stabilized zirconia-based sensor utilizing SnO2-based sensing electrode with an integrated $\mathrm{Cr}_{2} \mathrm{O}_{3}$ catalyst layer for sensitive and selective detection of hydrogen. International Journal of Hydrogen Energy 38(1): 305-312.

31. Hoa N, An S, Dung N, Quy N, Kim D (2010) Synthesis of p-type semiconducting cupric-oxide thin films and their application to hydrogen detection. Sensors and Actuators B 146(1): 239-244.

32. Hunga C, Tsai T, Chenb H, Tsai Y, Chena T, et al. (2008) Temperaturedependent hydrogen sensing characteristics of a new Pt/InAlAs Schottky diode-type sensor. Sensors and Actuators B 128(2): 574-580.

33. Salehi A, Nikfarjam A, Kalantari D (2006) Pd/porous-GaAs Schottky contact for hydrogen sensing application. Sensors and Actuators B 113(1): 419-427.

34. Lin K, Chenb H, Cheng C, Chuang H, Lu C, et al. (2003) Characteristics of a new Pt/oxide/In0.49Ga0.51P hydrogen sensing Schottky diode. Sensors and Actuators B 94: 145-151.

35. Chen H, Chou Y, Hsiun C (2003) Comprehensive study of adsorption kinetics for hydrogen sensing with an electroless-plated Pd-InP Schottky diode. Sensors and Actuators B 92(1-2): 6-16.

36. B Lysona, Gwizdza P, Czaplaa A, Lubeckaa M, Zakrzewskaa K, et al. (2011) $\mathrm{TiO}_{2}$ : $\mathrm{Cr}$ nanopowders for hydrogen sensing. Procedia Engineering 25: 749-752.

37. Jun RH, Wei CH, Yeong JC, Tzong BW, Kun WL, et al. (2006) Comparison of hydrogen sensing characteristics for Pd/GaN and Pd/Al0.3Ga0.7As Schottky diodes. Sensors and Actuators B 11:7151-158.

38. Fasaki I, Suchea M, Mousdis G, Kiriakidis G, Kompitsas M (2009) The effect of $\mathrm{Au}$ and $\mathrm{Pt}$ nanoclusters on the structural and hydrogen sensing properties of $\mathrm{SnO}_{2}$ thin films. Thin Solid Films 518(4): 1109-1113.

39. Jun J, Chou B, Lin J, Phipps A, X Shengwen, Ngo K, et al. (2007) A hydrogen leakage detection system using self-powered wireless hydrogen sensor nodes. Solid-State Electronics 51(7): 1018-1022.

40. Yan T, Chin C, Po Hsien L, Ssu I F, Ching H, etal. (2007) Comprehensive study of hydrogen sensing characteristics of Pd metal-oxide-semiconductor (MOS) transistors with Al0.24Ga0.76As and In0.49Ga0.51P Schottky contact layers. Sensors and Actuators B 120(2): 687-693.

41. Subodh S, Sumit K, Singh VN, Singh M, Vijay YK (2011) A Synthesis and characterization of $\mathrm{TiO}_{2}$ doped poly-aniline composites for hydrogen gas sensing. International Journal of Hydrogen Energy 36(10): 6343- 6355.

42. Kamloth K (2008) Semiconductor junction gas sensors. Chemical Reviews 108(2): 367-399.

43. Cheng C, Tsai Y, Lin K, Chen H, Hsu W, et al. (2004) Hydrogen sensing characteristics of Pd- and Pt-Al0.3Ga0.7As metal semiconductor (MS) Schottky diodes. Semiconductor Science and Technology 19(6): 778782 .

44. Basu S, Roy S, Jacob C (2004) Ruthenium as Schottky metal for SiC-based high temperature hydrogen sensors. Materials Technology 801:193-198.

45. Kim J, Gila B, Chung G, Abernathy C, Pearton S, Ren F (2003) Hydrogen sensitive GaN Schottky diodes. Solid State Electron 47(6): 1069-1073.

46. Ito K (1979) Hydrogen sensitive Schottky barrier diodes. Surface Science 86(2): 345-352 
47. Lo C, Tan S, Wei C, Tsai J, Hsu K, Lour W (2012) Unidirectional sensing characteristics of structured AueGaNePt diodes for differential pair hydrogen sensors. International Journal of Hydrogen Energy 37: 1857918587.

48. Trinchi A, Kandasamy S, Wlodarski W (2008) High temperature field effect hydrogen and hydrocarbon gas sensors based on SiC MOS devices. Sensors and Actuators B: Chem 133(2): 705-716.

49. Fardindoost S, zad A, F Rahimi, Ghasempour R (2010) Pd doped WO films prepared by sol-gel process for hydrogen sensing. International Journal of Hydrogen Energy 35(2): 854-860

50. Chen T, Chen H, Huang C, Hsu C, Chiu P, et al. (2011) Improved hydrogensensing performance of a Pd/GaN Schottky diode with a surface plasma treatment approach. Sensors and Actuators B 159(1): 159-162.

51. Hsu C, Lin K, Chen H, Chen T, Huang C, et al. (2011) On a heterostructure field-effect transistor (HFET) based hydrogen sensing system International Journal of Hydrogen Energy 36(24): 15906-15912.

52. Firth J, Jones A, Jones $\mathrm{T}$ (1973) The principles of the detection of flammable atmospheres by catalytic devices. Combustion and Flame 20(3): 303-311.

53. Jones E, Moseley P, Hilger A (1987) The pellistor catalytic gas detection In: Solid State Gas Sensors 17-31.

54. Katti V, Debnath A, Gadkari S, Gupta S, Sahni V (2002) Passivated thick film catalytic type $\mathrm{H}_{2}$ sensor operating at low temperature. Sensors and Actuators B: Chem 84(2): 219-225

55. Nishiboria M, Shina W, Izua N, Itoha T, Matsubaraa I, et al. (2009) Robust hydrogen detection system with a thermoelectric hydrogen sensor for hydrogen station application. International Journal of Hydrogen Energy 34(6): 2834-2841.

56. I Simon, M Arndt (2002) Thermal and gas-sensing properties of a micromachined thermal conductivity sensor for the detection of hydrogen in automotive application, Sensors and Actuators A 97-98: 104-108.

57. Nishibori M, Woosuck Shin, Noriya Izu, Toshio Itoh, Ichiro Matsubara, et al. (2010) Thermoelectric hydrogen sensors using Si and SiGe thin films with a catalytic combustor. Ceramic Society of Japan 118: 188-192.

58. Qiu F, Shin W, Matsumiya M, Izu N, Matsubara I, Murayama N (2004) Miniaturization of thermoelectric hydrogen sensor prepared on glass substrate with low-temperature crystallized SiGe film. Sensors and Actuators B: Chem 103(1-2): 252-259.

59. Shin W, Kiyohisa Imai, Noriya Izu, Norimitsu Murayama (2001) Thermoelectric thick-film hydrogen gas sensor operating at room temperature. Japanese Journal of Applied Physics 2001; 40:1232-1234.

60. Matsumiya M, Qiu F, Shin W, Izu N, Murayama N, Kanzaki S (2002) Thinfilm Li-doped $\mathrm{NiO}$ for thermoelectric hydrogen gas sensor. Thin Solid Films 419(1): 213-217.

61. Tajima K, Qiu F, Shin W, Izu N, Matsubara I, Murayama N (2005) Micromechanical fabrication of low-power thermoelectric hydrogen sensor. Sensors and Actuators B: Chemical 108(2): 973-978.

62. Meo F, Ing Shin Barry Chen, Philip Chen, Jeffrey Neuner, Andreas Roerhl, et al. (2006) MEMS-based hydrogen gas sensors. Sensors and Actuators B: Chemical 117(1): 10-16

63. Yang M, Liu H, Zhang D, Tong X (2010) Hydrogen sensing performance comparison of Pd layer and Pd/WO3 composite thin film coated on side-polished single- and multimode fibers. Sensors and Actuators B 149(1):161-164

64. Hernandez D, Moreno D, Escobar D, Villatoro J (2010) Optical microfibers decorated with Pd-Au nanoparticles for fast hydrogen sensing. Sensors and Actuators B 151: 219-222.

65. Wei X, Wei T, Xiao H, Lin Y (2011) Terbium doped strontium cerate enabled long period fiber gratings for high temperature sensing of hydrogen. Sensors and Actuators B 152: 214-219.
66. Sakaue H, Huang C, Sullivan J (2011) Optical hydrogen sensing method using temperature-sensitive luminophore on porous palladium. Sensors and Actuators B 155(1): 372-374

67. Casey V, Cleary J, Arcy G, Monagle J (2003) Calorimetric combustible gas sensor based on a planar thermopile array: fabrication, characterization, and gas response. Sensors and Actuators B: Chem 96 (1-2):114-123.

68. Gupta R, Sagade A, Kulkarni G (2012) Technical Communication A low cost optical hydrogen sensing device using nano crystalline Pd grating. International Journal of Hydrogen Energy 37: 9443-9449.

69. Hughes R, Schubert W (1992) Thin films of Pd/Ni alloys for detection of high hydrogen concentrations. Japanese Journal of Applied Physics 71(1):542-544

70. Kumar M, Rao M, Ramaprabhu S (2006) Structural, morphological and hydrogen sensing studies on pulsed laser deposited nano-structured palladium thin films. Japanese Journal of Applied Physics 39: 2791-2795.

71. MacIntyrea I, Tchouvelevb A, Hayc D, Wongd J, Grante J, et al. (2007) Canadian hydrogen safety program, International Journal of Hydrogen Energy 32(13): 2134-2143.

72. Ram B Gupta (2008) Hydrogen Fuel-Production, Transport, and Storage. Taylor and Francis Group.

73. Favier F, Walter E, Zach M, Benter T, Penner R (2001) Hydrogen sensors and switches from electrodeposited palladium mesowire arrays. Science 293(5538): 2227-2231.

74. Joshi R, Krishnan S, Yoshimura M, Kumar A (2009) Pd nanoparticles and thin films for room temperature hydrogen sensor. Nanoscale Research Letters 4(10): 1191-1196.

75. Prakash J, Daniel A, Horn M, Pilione L, Sunal P, et al. (2007) Hydrogen sensors: role of palladium thin film morphology. Sensors and Actuators B: Chem 120(2): 439-446.

76. Xu T, Zach M, Xiao Z, Rosenmann D, Welp U, et al. (2005) Self-assembled monolayer-enhanced hydrogen sensing with ultrathin palladium films. Applied Physics Letters 86: 203104.

77. Suzuki A, Kurokawa A, Nonaka H, Ichim S (2006) A possible hydrogen sensing method with dual pressure gauges. Sensors and Actuators A $127(1): 37-40$.

78. Han C, Hong D, Gwak J, Han S (2007) A planar catalytic combustion sensor using nano-crystalline F-doped $\mathrm{SnO}_{2}$ as a supporting material for hydrogen detection. Korean Journal of Chemical Engineering 24(6): 927-931.

79. Han C, Hong D, Kim I, Gwak J, Han S, et al. (2007) Synthesis of Pd or $\mathrm{Pt} /$ titanate nanotube and its application to catalytic type hydrogen gas sensor. Sensors and Actuators B: Chem 128(1): 320-325.

80. Shivaraman M, Lundstrom I, Svensson C, Hammarsten H (1976) Hydrogen sensitivity of palladium thin-oxide silicon Schottky barriers. Electronics Letters 12(18): 483-484.

81. Steele M, MacIver B (1976) Palladium/cadmium-sulfide Schottky diodes for hydrogen detection. Applied Physics Letters 28(11): 687-1687.

82. Kim S, Park J, Choi S, Kim H, Na H, et al. (2011) Room temperature sensing properties of networked GaN nanowire sensors to hydrogen enhanced by the $\mathrm{Ga}_{2} \mathrm{Pd}_{5}$ nanodot functionalization. International Journal of Hydrogen Energy 36(3): 2313- 2319.

83. Tan S, Tsaib J, Lai S, Lo C, Lour W (2011) Hydrogen-sensitive sensor with stabilized Pd-mixture forming sensing nanoparticles on an interlayer. International Journal of Hydrogen Energy 36(23): 15446-15454.

84. Huang B, Lin T (2011) A novel technique to fabricate horizontally aligned CNT nanostructure film for hydrogen gas sensing. International Journal of Hydrogen Energy 36(24):15919- 15926.

85. Landucci G, Tugnoli A, Cozzani V (2010) Safety assessment of envisaged systems for automotive hydrogen supply and utilization. International Journal of Hydrogen Energy 35(3):1493-1505. 
86. Hunter GW (1992) A Survey and Analysis of Commercially Available Hydrogen Sensors. NASA Technical Memorandum p. 1-22.

87. Boon Brett L, Bousek J, Moretto P (2009) Reliability of commercially available hydrogen sensors for detection of hydrogen at critical concentrations: part II-selected sensor test results. International Journal of Hydrogen Energy 34(1): 562-571.

88. Ishimoto J, Ohira K, Okabayashi K, Chitose K (2008) Integrated numerical prediction of atomization process of liquid hydrogen jet. Cryogenics 48(5-6): 238-247.

89. Barley CD, Gawlik K (2009) Buoyancy-driven ventilation of hydrogen from buildings: laboratory test and model validation. International Journal Hydrogen Energy 34(13): 5592-5603.

90. Gupta S, Brinster J, Studer E, Tkatschenko I (2009) Hydrogen related risks within a private garage: concentration measurements in a realistic fullscale experimental facility. International Journal Hydrogen Energy 34(14): 5902-5911.

91. Middha P, Hansen OR (2009) CFD simulation study to investigate the risk from hydrogen vehicles in tunnels. International Journal Hydrogen Energy 34(14): 5875-5886.

\section{ISSN: 2574-1241}

DOI: 10.26717/BJSTR.2019.21.003670

Yousef SH Najjar. Biomed J Sci \& Tech Res

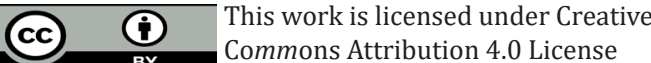

Submission Link: https://biomedres.us/submit-manuscript.php
92. Lowesmith B, Hankinson G, Spataru C, Stobbart M (2009) Gas build-up in a domestic property following releases of methane/hydrogen mixtures. International Journal Hydrogen Energy 34(14): 5932-5939.

93. Matsuura K, Kanayama H, Tsukikawa H, Inoue M (2008) Numerical simulation of leaking hydrogen dispersion behavior in a partially open space. International Journal Hydrogen Energy 33(1): 240-247.

94. Matsuura K, Nakano M, Ishimoto J (2009) The sensing-based adaptive risk mitigation of leaking hydrogen in a partially open space. International Journal Hydrogen Energy 34(20): 8770-8782.

95. Matsuura K (2009) Effects of the geometrical configuration of a ventilation system on leaking hydrogen dispersion and accumulation. International Journal Hydrogen Energy 34(24): 9869-9878.

96. Matsuura K, Nakano M, Ishimoto J (2010) Forced ventilation for sensingbased risk mitigation of leaking hydrogen in a partially open space. International Journal Hydrogen Energy 35(10): 4776-4786.

\begin{tabular}{ll}
\hline $\begin{array}{l}\text { BIOMEDICAL } \\
\text { RESEARCHES }\end{array}$ & Assets of Publishing with us \\
\hline - Global archiving of articles \\
\hline
\end{tabular}

